\title{
APPLICATION OF MOBILE PHONE-BASED PORTABLE MICROSCOPY IN CLINICAL HISTOPATHOLOGY: A FEASIBILITY STUDY
}

\author{
Waliullah A S M \\ Department of Biomedical Science and Engineering, Gwangju Institute of Science and Technology (GIST), \\ Gwangju-61005, South Korea.
}

\section{ABSTRACT}

Objectives: To check the feasibility of using mobile phone-based microscopy for various types of human histopathological sample investigations. Methodology: A feasibility study was performed by imaging several histopathological samples with one novel type of microscope "Foldscope" and image compared with a conventional microscope in the laboratory facility. The image acquired from both sources were edited further and put together for comparison. Results: Mobile phone- based microscope acquired images were observed and compared with a conventional microscope and found morphology of the tissue sections were significantly similar as of conventional light microscope images. Conclusion: By comparing the image of some non-human histopathological sample, it could be stated that this method is also feasible for human histopathological sample investigations, especially in the low resource area or in case of emergency situations.

KEYWORDS: Mobile phone-based microscopy; Histopathology; Microscopy; Imaging.

\section{INTRODUCTION}

Microscopic imaging is an essential part of the pathological investigation and diagnosis. There are a lot of purpose-specific microscopic modalities are available for pathological investigations. In general, conventional light microscopy is used for histopathological investigations. However, this microscopic modality is not available always in all health centers, especially in a rural and remote area with limited healthcare settings. Highly skilled and trained microscopist is required for proper microscopic histopathological investigation, which is not always possible in rural areas. Also in an emergency or catastrophic situations, it is not always possible to use the microscope for histopathological investigations due to resource limitation. Mobile phone-based microscopy could be one solution to overcome this health sector limitation in a rural area. In the recent years, there were some advancements of mobile phone-based microscopy [1] for rural consequences, such as for the diagnosis of Schistosoma haematobium [2], malaria [3], Giardia lamblia [4] through mobile phone-based microscopy. But the resolution and usefulness of this microscope are not only limited to urine, water or stool sample analysis, but also in histopathological investigations. Here we proposed

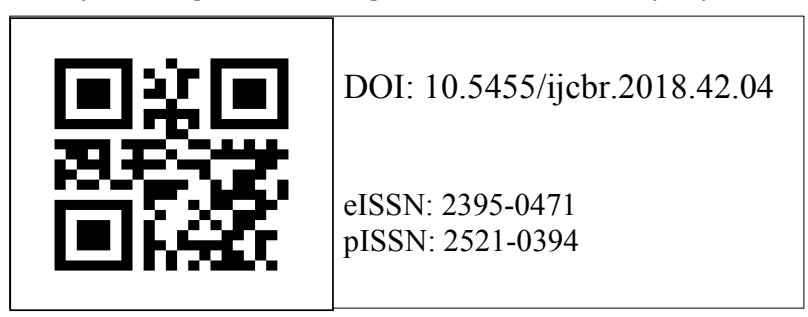

and checked the feasibility of one such kind of mobile phone-based microscope "Foldscope" [5] for some clinical histopathological investigations. As this microscope are easy to use, cheaper and portable so pathologists could adapt its assembly and imaging after few training.

Aim: This study was aimed to check the feasibility of using mobile phone-based portable microscope "Foldscope" for histopathological investigations.

Objectives: 1 . To observe the non-clinical samples under the mobile phone-based microscopy. 2. To find the feasibility of using mobile phone-based microscopy for human histopathological samples by comparing with the findings with non-clinical samples.

\section{MATERIALS AND METHODS}

Study design: Feasibility study.

Samples: Histology slide of frog blood, bone cell section, artery section were used as sample to find the feasibility of using mobile-phone based microscopy for human samples in future. These histology samples were kindly provided with Foldscope toolkits which were bought from Foldscope instruments, Inc. (San Francisco, CA).

Materials: One commercial handheld, portable optical origami types optical microscope, named "Foldscope" was used to conduct this study. This foldscope was bought from Foldscope instruments, Inc. (San Francisco, CA). Mobile-phone (Samsung Galaxy S6 edge, Samsung, Korea) was coupled with the foldscope by using

Correspondence: Waliullah A S M, Research Assistant, Department of Biomedical Science and Engineering, Gwangju Institute of Science and Technology (GIST), 123 Cheomdangwagi-ro, Buk-gu, Gwangju-61005, South Korea. Email: wali.rubmb10@gmail.com 
Figure 1,2, and 3. Foldscope and Leica DM IL LED captured image of blood, artery and bone sections respectively

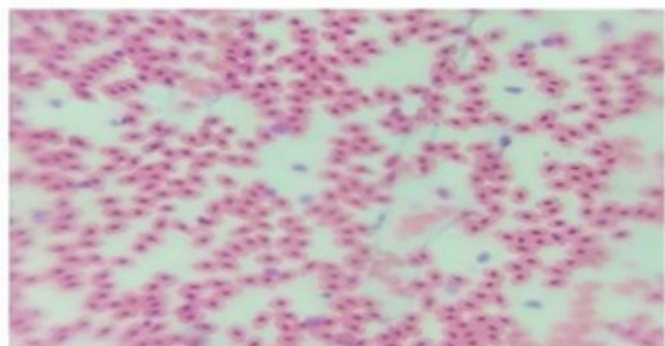

Foldscope captured image

(No zoom in phone camera)

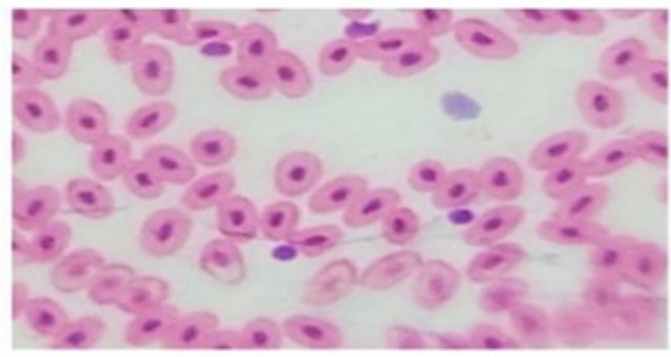

Foldscope captured image

(4X zoom in phone camera)

(a)

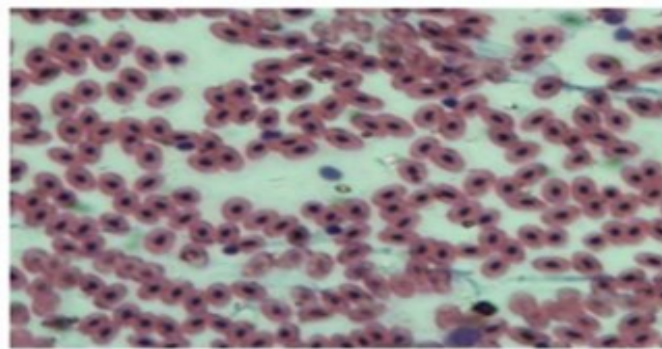

Leica DM IL LED captured image (5X objective lens)

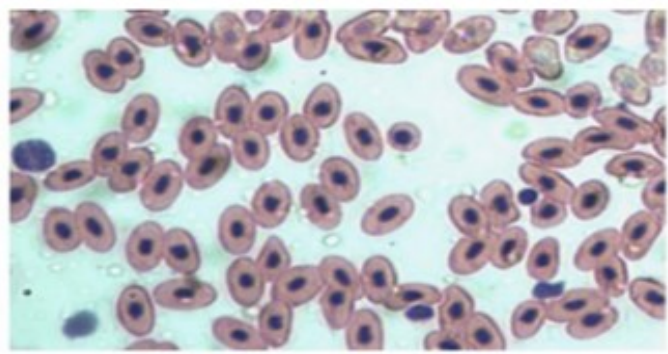

Leica DM IL LED captured image (10X objective lens)

(b)

Figure 1. Foldscope (a) and Leica DM IL LED (b) captured images of frog blood

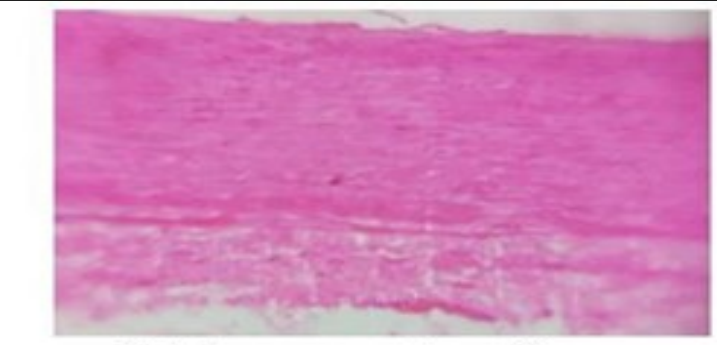

Foldscope captured image

(No zoom in phone camera)

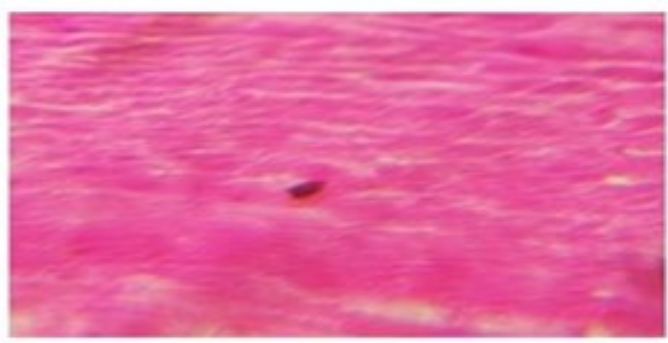

Foldscope captured image ( $4 \mathrm{X}$ zoom in phone camera)

(a)

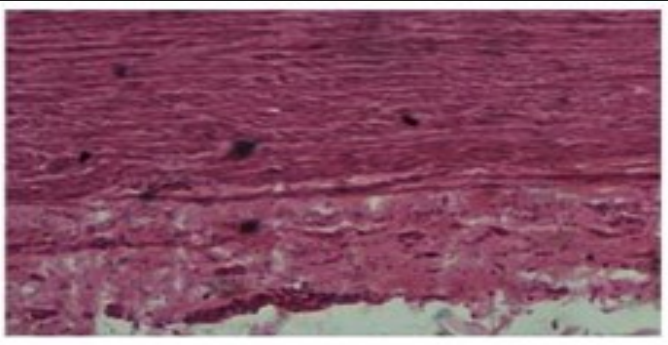

Leica DM IL LED captured image ( 5 X objective lens)

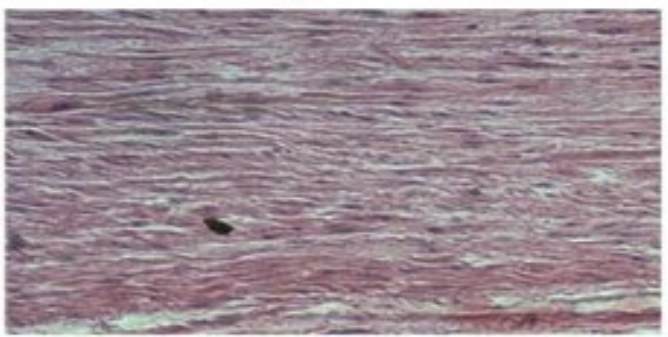

Leica DM IL LED captured image (10X objective lens)

(b)

Figure 2. Foldscope (a) and Leica DM IL LED (b) captured images of frog artery

tape and magnetic coupler for taking image of the histology samples (figure 4 and 5). The Foldscope was manually panned and focused according to the guideline of the manufacturer. Leica DM IL LED microscope coupled with CMOS camera (IMAGINGSOURCE ${ }^{\circ}$ DFK 72BUC02) was used to get standard image for comparison with the foldscope obtained images.

Methodology: Raw foldscope paper was open and assembled in order to conduct this study. After assembly, each histology slides were being imaged through Foldscope and mobile phone. Then the same slides also being imaged in Leica DM IL LED microscope as reference image.

Image Processing: All images were saved in JPEG format and further processed where needed in Adobe Photoshop CS6 (Adobe Systems). 


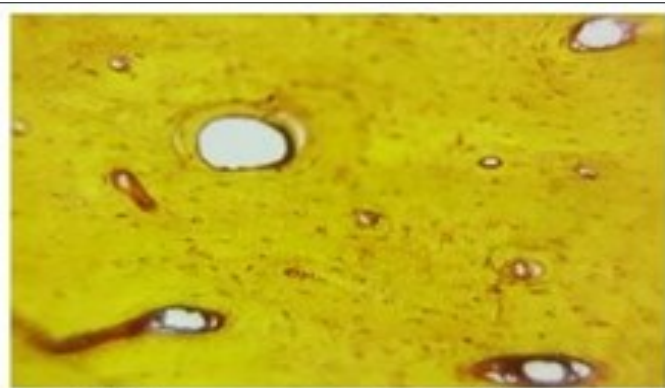

Foldscope captured image (No zoom in phone camera)

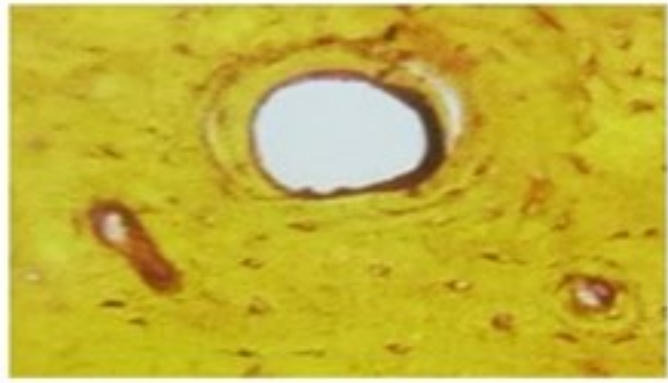

Foldscope captured image

( $4 \mathrm{X}$ zoom in phone camera)

(a)

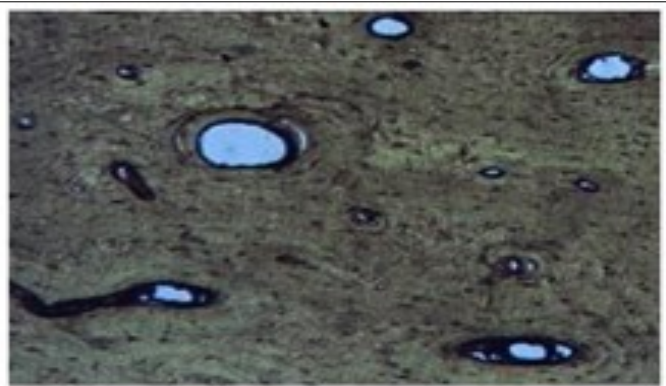

Leica DM IL LED captured image (5X objective lens)

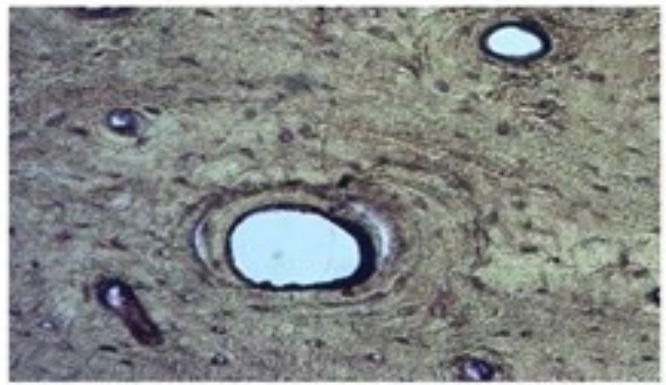

Leica DM IL LED captured image (10X objective lens)

(b)

Figure 3. Foldscope (a) and Leica DM IL LED (b) captured images of frog bone

\section{RESULTS}

Histology slide of frog blood, bone cells, and artery sections were subjected to image in Foldscope. These images were taken without internal illumination of the samples. In order to do that, we used room's general fluorescent lamp light and imaged opposite of the white background of the wall for the even illumination. The mobile-phone captured images of the histology slide of frog bloods, artery section, bone sections are illustrated in ' $a$ ' panel of figure 1, 2 and 3.

Also, the same histology sample slides were imaged under the Leica DM IL LED microscope. It's coupled CMOS camera obtained images are illustrated in ' $b$ ' panel of figure 1,2 and 3. We observed this two modality acquired images and compared them.

Morphology of the tissue sections was found significantly similar as of conventional light microscope. Which showed the strong feasibility of using this mobile phone-based microscope in future for the clinical histopathological investigations with several human histology samples.

\section{DISCUSSION}

Simple, cheap and precise diagnostic tests are challenging factor in the low resource-setting area [6] or in emergency situation. This mobile phone-based imaging modality could play a role to contribute to this challenge. Here we demonstrated one type of com-

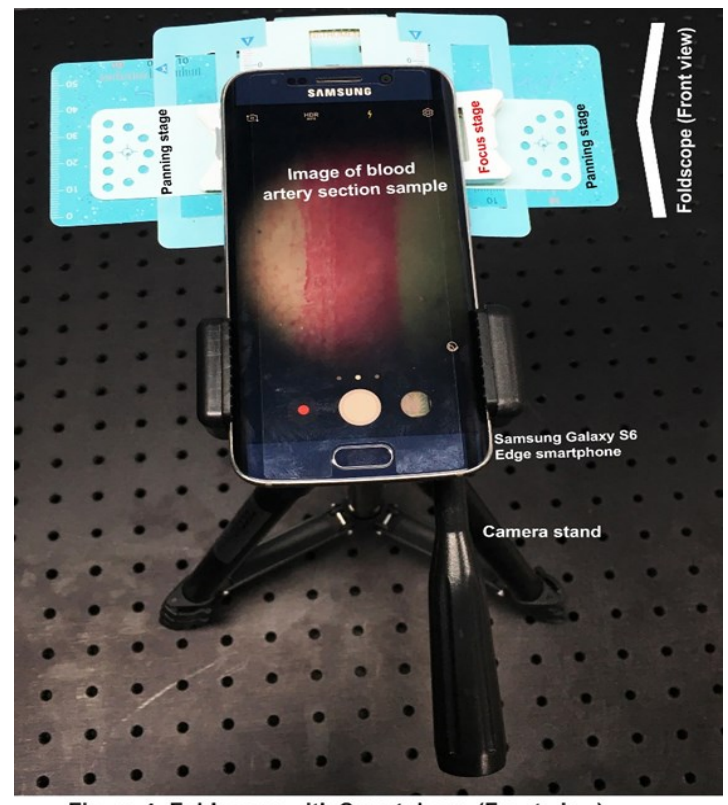

Figure 4: Foldscope with Smartphone (Front view)

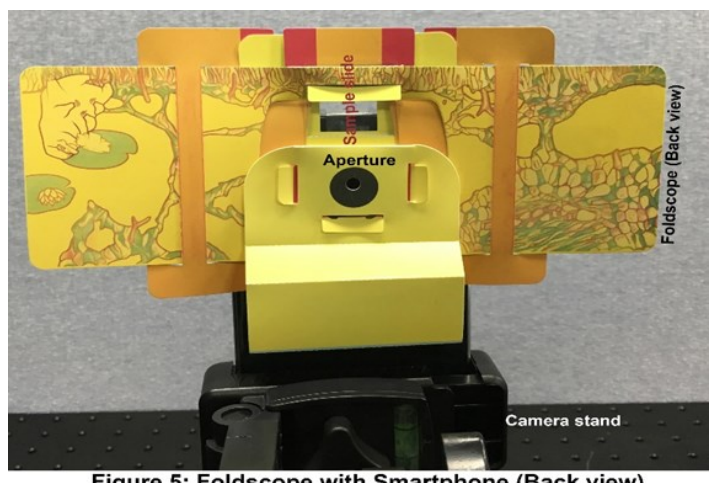

Figure 5: Foldscope with Smartphone (Back view) 
mercial mobile phone-based microscope for checking the feasibility of using this method for human histopathological investigations [7].

The images acquired with Foldscope are little bit low contrast as compared to the conventional light microscopy acquired images. The reason is the absence of internal light source in the Foldscope. The foldscope has the option to use LED as light source during imaging, but here we tried to use rooms general light in order to mimic the situation more comparable with a remote area or in catastrophic situation where pathologists are not only dependent on LED illumination, but also the could able to use the device in daylight or electric fluorescent light. But it is possible to improve the image quality by using its own LED as a light source during the investigations. The mobile phone-based imaging device 'Foldscope' use ball lens for convenient use and its magnification capacity is $140 x$ and the resolution of the 'Foldscope' is $2 \mu \mathrm{m}$. The image and observation acquired in this study, reveals that this magnification is enough to the histopathological investigation of human blood sample, as human RBC diameter is 6.2-8.2 $\mu \mathrm{m}$ [8], eosinophil diameter is $12-17 \mu \mathrm{m}$ [9] and neutrophils average diameter is $8.85 \mu \mathrm{m}$ [10]. So the use of this mobile phone-based microscopy is feasible for human blood morphology or function related histopathological investigations.

Also, image acquired from our study demonstrates that this method is also feasible for human bone cell's histopathological investigations as human bone cell (osteoclast) is about 150-200 $\mu \mathrm{m}$ [11] in diameter. This mobile phone-based microscopy is very much compatible with this size of bone cells.

Also, this study showed the feasibility of using this mobile phone-based microscopy for human artery muscle cells as their diameter is less than 250 to 300 $\mu \mathrm{m}$ [12]. Also imaging of capillary is also feasible as their diameter is about $5 \mu \mathrm{m}$ [13] inside.

Hence physicians can use this mobile phone-based microscopy for their histopathological examinations of the tissue samples beyond the requirement of the expensive optical microscope and with low resource clinical settings. Even pathologist can easily detect the tissue abnormality by analyzing the mobile phone microscope obtained images in mobile phone apps [14]. Past few years, there was a lot of contribution to the development and implications of the mobile phone-based microscope. Even automated clinical diagnosis methods also reported through mobile phonebased microscopes [15]. In this way, this portable and handheld microscopy could create a new dimension in the rural health sector.

\section{CONCLUSION}

These microscopic techniques are varied based on their size, price, resolution, portability, etc. In this study, we checked the feasibility of using one novel type of mobile phone-based microscope. By comparing the image of some non-human histopathological sample, it could be concluded that this method is also feasible for human histopathological sample investigations. With further improvement and modification, this novel method may be much helpful option in precise and urgent histopathological image investigation modality for resource- limited health settings.

Acknowledgements: I acknowledge GIST for its kind support and funding for my study.

\section{Source of funding: None}

\section{Conflict of Interest: None.}

\section{REFERENCES}

1) Breslauer DN, Maamari RN, Switz NA, Lam WA, Fletcher DA. Mobile phone based clinical microscopy for global health applications. PLOS ONE. 2009; 4.7: e6320.

2) Bogoch II, Ephraim RKD, Tseng D, Koydemir HC, Ozcan, A, Andrews JR., et al. Evaluation of a Mobile Phone-Based Microscope for Screening of Schistosoma haematobium Infection in Rural Ghana. The American Journal of Tropical Medicine and Hygiene. 2017; 96(6): 1468-1471.

3) Pirnstill, Casey W., and Gerard L. Coté. Malaria Diagnosis Using a Mobile Phone Polarized Microscope. Scientific Reports. 2015; 5(1): 13368

4) Koydemir, HC, Gorocs Z, Tseng D, Cortazar B, Feng $S$, Chan RYL et al. Rapid imaging, detection and quantification of Giardia lamblia cysts using mobile- phone based fluorescent microscopy and machine learning. Lab on a Chip. 2015; 15(5): 1284 $-1293$.

5) Cybulski JS, Clements J, Prakash M. Foldscope: origami-based paper microscope. PLoS ONE. 2014; 9 (6): e98781.

6) Petti CA, Polage CR, Quinn TC, Ronald AR, Sande MA. Laboratory medicine in Africa: a barrier to effective health care. Clinical Infectious Diseases. 2006; 42(3): 377-382.

7) Shaw PA, \& Friedman E S. Clinico-Histologic Conferences: Histology and disease. Anatomical Sciences Education. 2011; 5(1): 55-61.

8) Mary Louise Turgeon. Clinical Hematology: Theory and Procedures. Lippincott Williams \& Wilkins. 2004; 100.

9) Uhm TG, Kim BS. Eosinophil Development, Regulation of Eosinophil-Specific Genes, and Role of Eosinophils in the Pathogenesis of Asthma. Allergy, Asthma \& Immunology Research. 2012; 4 (2): 6879.

10) Niemiec MJ, De Samber B, Garrevoet J, Vergucht E, Vekemans B, De Rycke R, et al., Trace element landscape of resting and activated human neutrophils on sub-micrometer level. Metallomics. 2015; 
7 (6): 996-1010.

11) Wang Z, McCauley LK. Osteoclasts and odontoclasts: signaling pathways to development and disease. Oral Diseases. 2011; 17(2): 129-42.

12) Swift MR, Weinstein BM. Arterial-venous specification during development. Circulation Research. 2009; 104 (5): 576-88.

13) Pavelka Margit, Jürgen Roth. Functional Ultrastructure: An Atlas of Tissue Biology and Pathology. Springer. 2005; 232.
14) Hartman D, Kolowitz B, Lauro G, McHugh J, Palat V, Pantanowitz, L. et al. Pocket pathologist: A mobile application for rapid diagnostic surgical pathology consultation. Journal of Pathology Informatics. 2014; 5(1): 10.

15) Linder E, Grote A, Varjo S, Linder N, Lebbad M, Lundin M, Diwan V, Hannuksela J, Lundin J. Onchip imaging of Schistosoma haematobium eggs in urine for diagnosis by computer vision. PLoS Neglected Tropical Diseases. 2013; 7(12): e2547

How to Cite this article: Waliullah A S M. Application of mobile phone-based portable microscopy in clinical histopathology: A feasibility study. Int. j. clin. biomed. res. 2018;4(2): 16-20. 